\title{
Article \\ Toward a Selective Analysis of Heavy Metal Salts in Aqueous Media with a Fluorescent Probe Array
}

\author{
Andrey G. Melnikov *, Denis A. Bykov, Alexey S. Varezhnikov (), Victor V. Sysoev*(i) and Gennady V. Melnikov \\ Department of Physics, Yuri Gagarin State Technical University of Saratov, 410054 Saratov, Russia; \\ robokop2468.bykov@yandex.ru (D.A.B.); alexspb88@mail.ru (A.S.V.); melnikov_gv@sstu.ru (G.V.M.) \\ * Correspondence: agmelnikov@yandex.ru (A.G.M.); vsysoev@sstu.ru (V.V.S.)
}

\begin{abstract}
Detection of heavy meals in aqueous media challenges worldwide research in developing particularly fast and affordable methods. Fluorescent sensors look to be an appropriate instrument for such a task, as recently they have been found to have made large progress in the detection of chemical analytes, primarily in the environment, along with biological fluids, which still suffer from not enough selectivity. In this work, we propose a new fluorescent method to selectively recognize heavy metals in an aqueous solution via employing an array of several fluorescent probes: acridine yellow, eosin, and methylene blue, which were taken as examples, being sensitive to a microsurrounding of the probe molecules. The exemplary sensor array generated six channels of spectral information through the use of various combinations of excitation and detection wavelengths. Following the known multisensor approach, we applied a linear discriminant analysis to selectively distinguish the vector signals from the sensor array from salts of heavy metals- $\mathrm{Cu}, \mathrm{Pb}, \mathrm{Zn}, \mathrm{Cd}$, and $\mathrm{Cz}$ - at the concentration ranges of $2.41 \times 10^{-6}-1.07 \times 10^{-5} \mathrm{M}, 2.8 \times 10^{-5}-5.87 \times 10^{-4} \mathrm{M}$, $1.46 \times 10^{-6}-6.46 \times 10^{-6} \mathrm{M}, 1.17 \times 10^{-8}-5.2 \times 10^{-8} \mathrm{M}$, and $2.11 \times 10^{-6}-9.33 \times 10^{-6} \mathrm{M}$, respectively. The suggested approach was found to be promising due to it employing only one cuvette containing the test solution, simplifying a sample preparation when compared to preparing a variety of solutions in tests with single fluorescence probes.
\end{abstract}

Keywords: fluorescence sensor; heavy metal; multisensor array; selectivity

Analysis of Heavy Metal Salts in

Aqueous Media with a Fluorescent

Probe Array. Sensors 2022, 22, 1465.

https://doi.org/10.3390/s22041465

Academic Editors: Antonios

Kelarakis and Ivo Grabchev

Received: 22 December 2021

Accepted: 10 February 2022

Published: 14 February 2022

Publisher's Note: MDPI stays neutral with regard to jurisdictional claims in published maps and institutional affiliations.

Copyright: (c) 2022 by the authors. Licensee MDPI, Basel, Switzerland. This article is an open access article distributed under the terms and conditions of the Creative Commons Attribution (CC BY) license (https:// creativecommons.org/licenses/by/ $4.0 /)$.

\section{Introduction}

At present, human activity leads to an increase in environmental pollution by various ecotoxicants including heavy metals. In this regard, the development and implementation of new methods that could allow one to register their presence are rather urgent [1]. There are three major types of environmental pollution, namely, in the atmosphere [2,3], in water [4], and in soil [5,6], of which liquid media is possibly the most challenging. Indeed, while some heavy metals have important biological functions in plants, animals, and humans [7], their chemical structure and redox properties lead sometimes to the fact that they can avoid mechanisms of their excretion from the body, such as homeostasis transport by proteins and binding to the necessary components of the cell [8]. These metals bind to regions of the protein, displacing the parent metals in their natural binding sites that cause malfunctioning of cells and has a toxic effect. For instance, previous studies have shown that an oxidative degradation of biological macromolecules appears primarily due to the binding of heavy metals to DNA and nuclear proteins [9]. Therefore, heavy metals are considered to be large toxicants that may damage multiple human organs even at low exposure levels. They are also classified as carcinogens to humans, known or probable, by the U.S. EPA and the International Agency for Research on Cancer [10]. Altogether, an early detection of heavy metal ions is considered an important task in order to protect the environment from pollution [11].

The conventional analytical methods capable of detecting metal ions primarily employ atomic absorption or emission spectroscopy (AAS/AES) [12], inductively coupled plasma 
mass spectrometry (ICP-MS) [13], anodic voltammetry [14], and capillary electrophoresis [15], which normally require expensive equipment and/or rather complex sample preparation, making it difficult to detect the ions in situ and under a real timescale. For example, atomic absorption spectroscopy (AAS) is widely utilized for detecting traces of heavy metal ions in all types of liquid samples such as food [16] and biological samples $[17,18]$. Ordinarily, it measures an individual chemical element in the course of a single measurement [19]. Unlike AAS, inductively coupled plasma (ICP) spectrometry is a multi-element analysis technique $[20,21]$. The major challenges while applying ICP techniques are the difficulties in separating the target isotopes due to a noise in the detectors to be accompanied by a relatively long time for the analysis. Further, laser spark emission spectrometry (LSES or LIBS) yields a rapid analysis of heavy metals in water as well as continuous monitoring of analytes via analyzing their spectral characteristics [22]. It makes it possible to simultaneously perform multi-element analysis with a high sensitivity of up to $2 \mathrm{ppm}[23,24]$. However, the formation of dissolved gases and bubbles by laser pulses can often lead to defocusing of the laser beam, limiting LIBS application thus far [11]. The most sensitive technique is based on neutron activation analysis (NAA), which employs the material's bombardment by neutrons in order to induce radioactive isotopes at a short half-life $[25,26]$. This method provides options to simultaneously identify many chemical elements without a chemical separation with a high sensitivity, up to 10ths of a nanogram per liter [27]. However, still, the NAA technique is difficult to employ in practice because the analysis requires radioactive substances that need special care. Finally, the potentiometric methods have attracted a considerable interest recently as an easier alternative with many possibilities for machine processing [28]. In particular, the voltammetric methods are widely employed in labs to register heavy metals $[29,30]$. However, in addition to high sensitivity, the potentiometric sensor arrays require special electrodes to be constantly monitored for their condition, which again limits their application.

Herein, we consider the technique that is matured from luminescent analysis to deliver information about the presence of heavy metals in a non-destructive manner, being extremely important for the analysis of biological objects [31,32]. This method employs a decreasing in the fluorescence intensity with the presence of heavy metals in the solution. Such a quenching is thought to be a result of intersystem crossing to an excited triplet state promoted by spin-orbit coupling of the excited (singlet) fluorophore and the halide upon contact [33], which is very sensitive to heavy metals contained in a solution [34]. In order for the selectivity of quantum yield of fluorescence to be advanced [35], there are two approaches, namely, (i) the molecular design of selective fluorescent probes [36-39] and (ii) applying new processing methods [40], which ensure the selective characteristics of fluorescence to a particular metal [41]; in particular, there is a high interest in designing multiband sensor array emission in a wide range of wavelengths [42]. The second direction involves using pattern recognition algorithms to process the vector signals generated by arrays of fluorescence sensors [43,44]. With such an option, it is possible to determine not only the presence of heavy metal ions but also to selectively recognize their kind. This method follows a general concept of the so-called "electronic tongue" [45,46], wherein fluorescent probes or quantum dots are selected so that the array includes probes that are sensitive to various metals. As a signal to process, the fluorescence intensities of the array are extracted to be further treated as a vector by, for instance, linear discriminant analysis (LDA) algorithm, one of the most powerful techniques for pattern recognition $[47,48]$. Similar LDA processing has been used when considering colorimetric methods to distinguish heavy metal ions in solutions [49]. Still, it is worth noting that utilization of a variety of solutions of the sample under study causes difficulties in the sample preparation and imposes advanced requirements to the initial volume of the sample. Furthermore, there is an effort to develop multisensors based on bacteria [50] in order to analyze the content of heavy metal ions in aqueous media, wherein researchers have used the influence of heavy metals on the growth of several selected cultures of bacteria. However, the noted measurements take a rather long time of around two days. Another example has been 
reported in [51], where the authors employed a multi-sensor composed of a number of synthesized fluorescence probes to selectively detect many compounds. Therefore, there is still a call for developing a method for a fast but selective recognition of heavy metal ions combined with a simple preparation of a sample.

In this work, we propose a sensor array based on three fluorescent probes to meet the noted call accounting for our preliminary findings [52], following a general scheme of the approach shown in Figure 1.
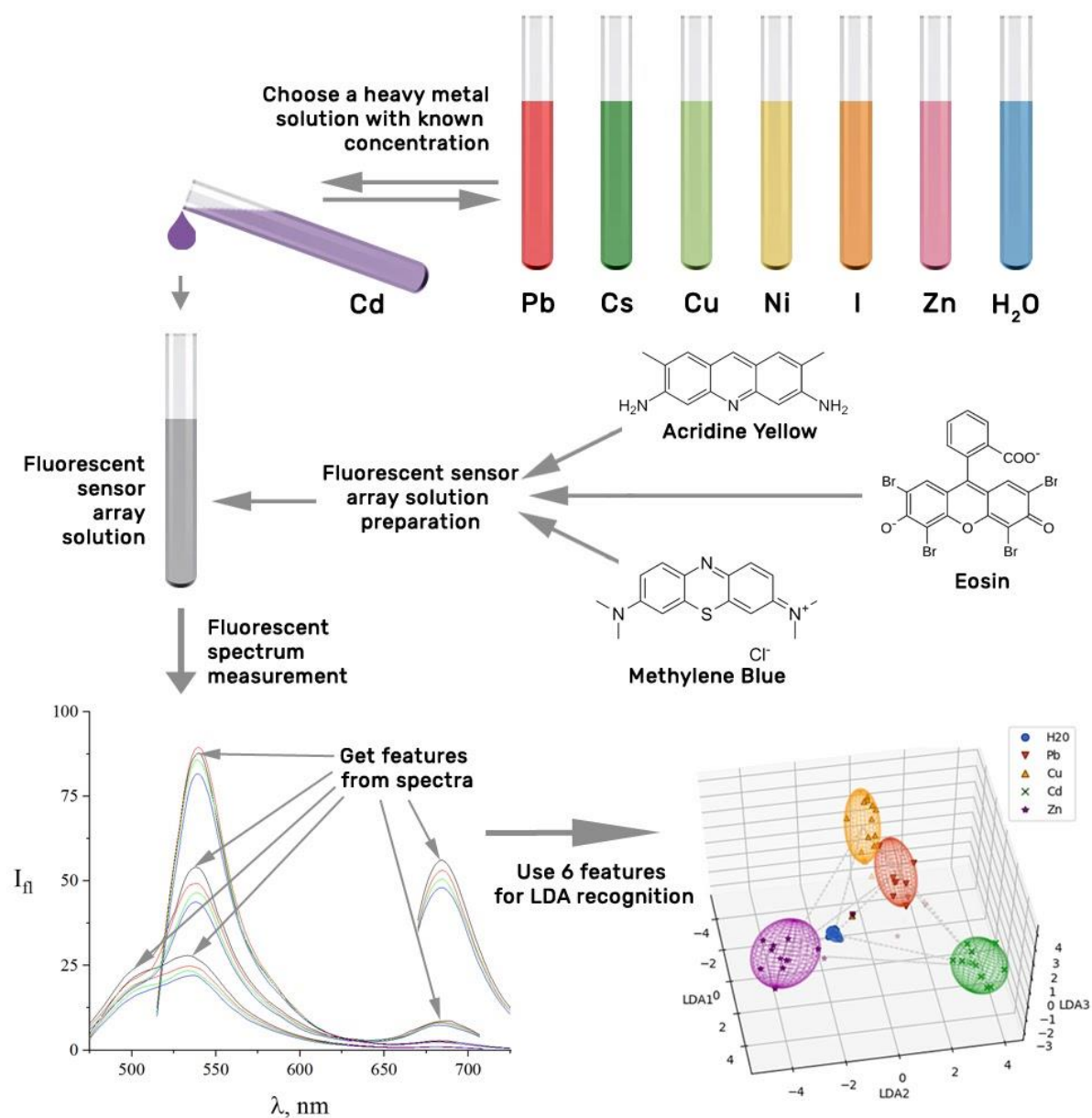

Figure 1. General scheme of the methodological approach.

As we show, the proposed multisensor array, a mixture of luminescent probes, yielded a multiple fluorescence response to heavy metal ions in a liquid in accordance with their concentration at the microenvironment of the dyes. The kind of the ions is selectively distinguished by LDA processing of the vector signals taken from the array after the calibration of the array upon to the ion impact.

\section{Materials and Methods}

To show the feasibility of the method, we considered three fluorescent dye probes, namely, eosin yellow, acridine yellow, and methylene blue (Sigma-Aldrich Pty Ltd., Darmstadt, Germany). These dyes have long been used for fluorescence studies due to their high sensitivity to changes on their microenvironment. For instance, eosin $Y$, bound to ligands, has been frequently used to register $\mathrm{Co}, \mathrm{Ag}, \mathrm{Zn}, \mathrm{Cd}$, and $\mathrm{Pb}$ ions via making triple complexes with these metals and ligands [53]. Moreover, eosin is widely employed in electrochemistry to create electrodes sensitive to $\mathrm{Cd}$ [54]. The acridine dyes and their derivatives are widely used as fluorescent and electrochemical sensors [55-57], as solar photocatalysts for enhancing biodegradability of toxic compounds [58], and for develop- 
ment of new fluorescent $\mathrm{pH}$ sensors [59]. Methylene blue is widely used in medicine [60] and as a near-infrared fluorescent probe [61,62]; its polarization is used as a quantitative marker of cancer at the cellular level [63]. The Figure 2 depicts the structural formulas of these compounds.<smiles>Cc1cc2cc3cc(C)c(N)cc3nc2cc1N</smiles>

(a)

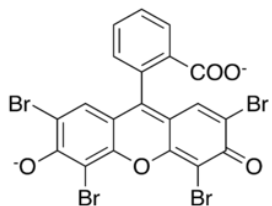

(b)

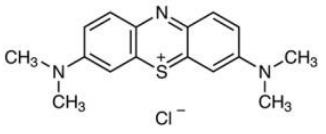

(c)

Figure 2. Structural formulas of dyes employed in the work to create the fluorescent probe array: (a) acridine yellow $\left(\phi=0.47, \lambda_{\mathrm{ex}}=445 \mathrm{~nm}, \lambda_{\mathrm{em}}=505 \mathrm{~nm}\right),(\mathbf{b})$ eosin $\left(\phi=0.67, \lambda_{\mathrm{ex}}=500 \mathrm{~nm}\right.$, $\left.\lambda_{\mathrm{em}}=545 \mathrm{~nm}\right)$, and $(\mathrm{c})$ methylene blue $\left(\phi=0.52, \lambda_{\mathrm{ex}}=660 \mathrm{~nm}, \lambda_{\mathrm{em}}=680\right)$.

These substances are common luminescent probes with a high quantum yield of fluorescence, being $\phi=0.47$ for acridine yellow [64], $\phi=0.67$ for eosin [65], and $\phi=0.52$ for methylene blue [66]. Moreover, these fluorophores yield various wavelengths of their fluorescence, which is a prerequisite for the successful and simple separation of signals to form a sensor array. When considering the concentration values of dyes, we accounted for following conditions: (i) exclusion of the influence of the internal filter, and (ii) the fluorescence maxima of the dyes upon excitation at a wavelength of $260 \mathrm{~nm}$, which should appear approximately at the same level. The dye solutions were prepared by diluting the pristine dry matter in a distilled water with further final adjusting of these initial solutions with water. The photochemical activity of the dyes was reduced to a minimum by maintaining a constant temperature and $\mathrm{pH}$. We controlled the process by measuring the absorption spectra and extracting the concentrations according to the Bouguer-Lambert-Beer law. Final concentrations of acridine yellow, eosin $\mathrm{Y}$, and methylene blue were $1.13 \times 10^{-7}, 9.21 \times 10^{-9}$, and $9.32 \times 10^{-7}$, respectively. Final concentrations of $\mathrm{Cu}, \mathrm{Pb}, \mathrm{Zn}, \mathrm{Cd}$, and $\mathrm{Cz}$ were in the ranges of $2.41 \times 10^{-6}-1.07 \times 10^{-5} \mathrm{M}, 2.8 \times 10^{-5}-5.87 \times 10^{-4} \mathrm{M}, 1.46 \times 10^{-6}-6.46 \times 10^{-6} \mathrm{M}$, $1.17 \times 10^{-8}-5.2 \times 10^{-8} \mathrm{M}$, and $2.11 \times 10^{-6}-9.33 \times 10^{-6} \mathrm{M}$, respectively.

In the course study, we took several basic solutions of heavy metal salts, copper $\left(\mathrm{Cu}\left(\mathrm{NO}_{3}\right)_{2}\right)$, lead $\left(\mathrm{Pb}\left(\mathrm{NO}_{3}\right)_{2}\right)$, zinc $\left(\mathrm{Zn}\left(\mathrm{NO}_{3}\right)_{2}\right)$, cadmium $\left(\mathrm{Cd}\left(\mathrm{NO}_{3}\right)_{2}\right)$, and cesium $(\mathrm{CsCl})$. These solutions have been prepared by diluting a required amount of dry matter (salts) in distilled water. To study the response of the fluorescent probes in the array to the presence of heavy metal ions, we added minor volumes of solutions, $0.1-0.5 \mathrm{~mL}$, containing these salts into the liquid containing the sensor array, of $3 \mathrm{~mL}$ volume, with further recording of the fluorescence spectra. These concentrations were chosen following a number of preliminary studies to be at the minimum level able to detect with the employed dyes. While performing the study, we tried to avoid photo-bleaching of the dyes by their proper conditioning: (i) the solutions were kept in a fridge in a light-isolated box; (ii) the time to prepare the probes and to measure the spectra of each sample was the same; (iii) the addition of salts of heavy metals to solutions of multi-probe array were prepared just before the experiment; and (iv) the time to record the spectra was chosen to exclude the spectra distortions.

The dye fluorescence spectra were measured with a high-resolution spectrometer (Perkin Elmer LS-55, PerkinElmer, Inc., Waltham, MA, USA). Excitation and emission slits were set to $10 \mathrm{~nm}$, and excitation wavelengths were varied in the range of 260-660 $\mathrm{nm}$ as described below. At an excitation wavelength of $260 \mathrm{~nm}$, we used an in-built emission filter at $350 \mathrm{~nm}$.

For the processing of vector signals generated by a fluorescent probe array, we used the LDA algorithm taken in the standard Python libraries of the scikit-learn package [67]. 


\section{Results and Discussion}

The major issue of concern in this work relates to advancing a selectivity of detecting metal ions in aqueous media with multiple fluorescent probes. The fluorescence of each luminescent probe taken to combine the array is a separate source of information on changes in the dye microsurrounding. The addition of several probes together with the solution makes possible to obtain more data in a single measurement. To yield the number of features from the fluorescent probe array for the ion recognition, we performed a fluorescence excitation at different wavelengths in the course of spectral measurements.

Figure 3 shows the fluorescence spectra of individual dye solutions and the fluorescence spectrum of their resulting mixture, a multiple probe array, upon excitations at $260 \mathrm{~nm}, 445 \mathrm{~nm}, 500 \mathrm{~nm}$, and $660 \mathrm{~nm}$ wavelengths.

\section{Fluorescence}

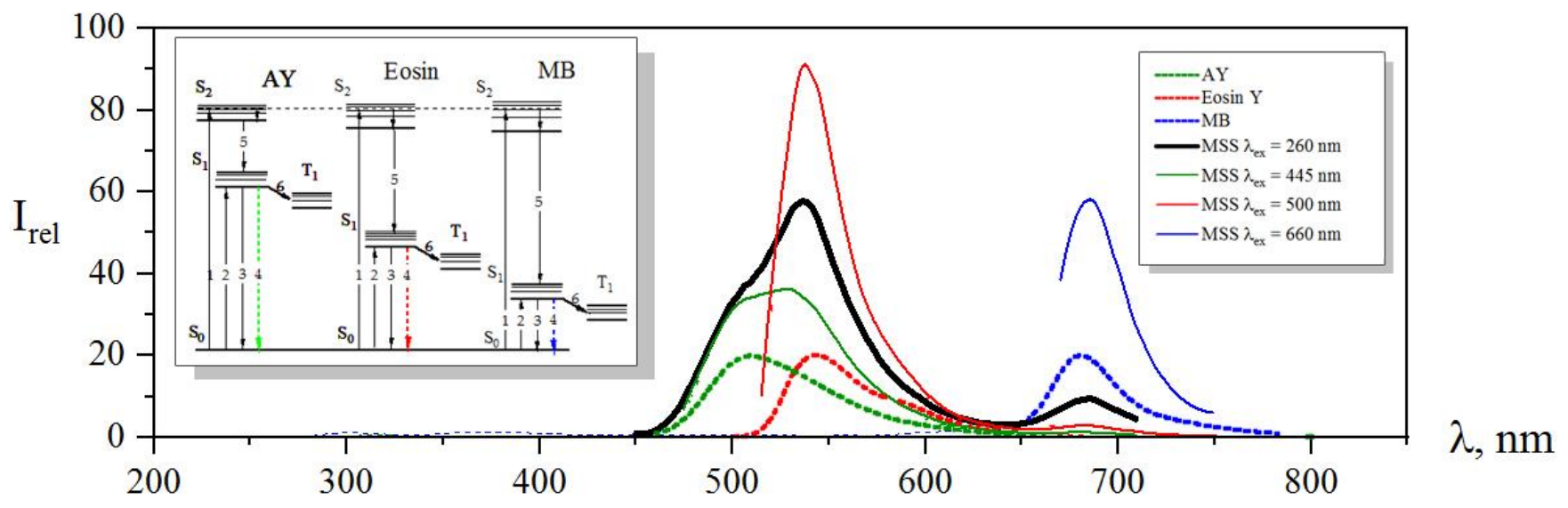

Figure 3. The fluorescence spectra of a fluorescent probe array under excitation at various wavelengths of $260 \mathrm{~nm}$ (black solid line), $445 \mathrm{~nm}$ (green line), $500 \mathrm{~nm}$ (red line), and $660 \mathrm{~nm}$ (blue line). The dotted lines mark fluorescence spectra of acridine yellow (green dotted), eosin (red dotted), and methylene blue (blue dotted), normalized to $I_{\text {rel }}=20$. The insert is an energy diagram illustrating the photophysical processes taking place in the system.

These excitation wavelengths were chosen as follows: At a wavelength of $260 \mathrm{~nm}$, all dyes of the array had an absorption peak related to $S_{0}-S_{2}$ transfer. Upon excitation, the electrons went to the $S_{2}$ excited level, as drawn in Figure 3, to be a process 1 at the energy diagram. Then, they dropped down to the $S_{1}$ state as a result of internal conversion (process 5) and further yielded a fluorescence (process 4), which was recorded by the spectrophotometer. In this case, fluorescence bands of all the three dyes were observed in the spectrum, and maxima of fluorescence intensities of the probe array were recorded at wavelengths of $505 \mathrm{~nm}, 540 \mathrm{~nm}$, and $685 \mathrm{~nm}$. These intensity values were employed as three primary features for the analyte recognition. When the fluorescent probe array was excited at wavelengths of $445 \mathrm{~nm}, 500 \mathrm{~nm}$, and $660 \mathrm{~nm}$, the dyes went into the S1 excited state (process 2) with subsequent appearing of fluorescence (process 4 ) again. These intensities of the maxima of all three probes were recorded with a spectrophotometer as secondary three features for an analyte recognition. Altogether, we had six features that could be employed for a sensitive response to changes in the microsurrounding of the probes. From a fundamental viewpoint, when ions of heavy metals in a liquid meet a dye molecule, the spin of the valence electron of the dye flips and it goes to a triplet state (process 6). As a result, the population of the $S_{1}$ state and the number of fluorescence transitions (4) reduced, and we observed a fluorescence quenching [33]. Thus, the influence of heavy metal ions on the fluorescent probes manifested itself upon excitation of the system in both $S_{1}$ and $S_{2}$. However, the quenching efficiency strongly depends on the nuclear charge of a metal atom: as a first approximation, the larger charge results in greater efficiency, 
making a fundamental background for the ion selectivity by analyzing a vector signal of the probe array.

Figure 4a displays spectra recorded under copper salt being added to the dye solution. As we see, a fluorescence quenching occurred in all the dyes of the array. The presented spectra showed that the quenching rate varied at different spectral fluorescence bands: for excitation on $260 \mathrm{~nm}$, acridine yellow peak decreased from 32 a.u. to 22 a.u., that is, by $30 \%$; eosin peak decreased from 56 a.u. to 46 a.u. (18\%); and methylene blue peak fell from 10 a.u. to 8 a.u. (20\%). It can be seen from the figure that acridine yellow and methylene blue fluorescence quenching went more rapidly than for eosin. For excitation at acridine yellow, the absorption peak at around $445 \mathrm{~nm}$ of its fluorescence maximum went down from 28 a.u. to 20 a.u., that is, by $28 \%$. For excitation at eosin yellow, absorption peak at around $500 \mathrm{~nm}$ of its fluorescence was reduced from 90 a.u. to 81 a.u. (28\%). When the excitation wavelength was set to $660 \mathrm{~nm}$, which corresponded to methylene blue absorption maximum, we observed quenching of its fluorescence from 64 a.u. to 53 a.u. $(17 \%)$. This shows the relevance of using multiple excitation wavelengths to increase the variability of the fluorescent probe array.

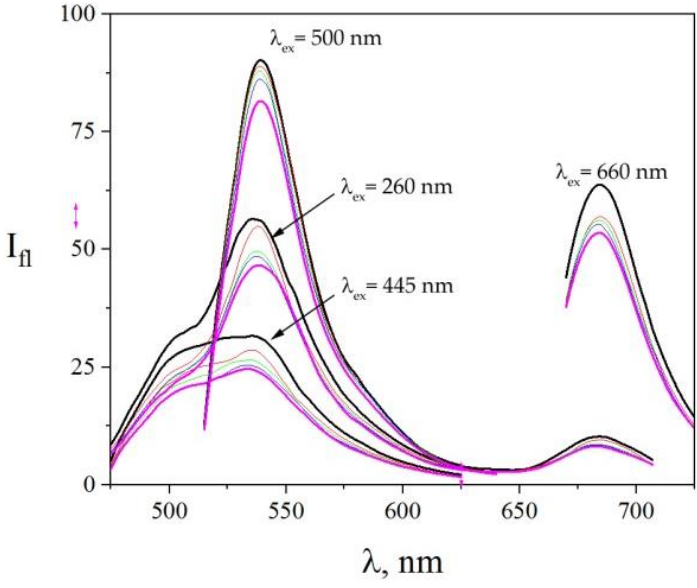

(a)

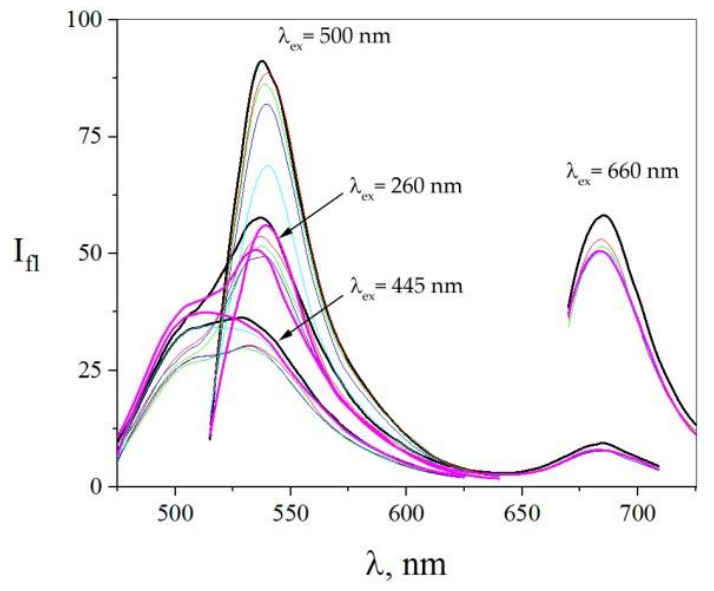

(b)

Figure 4. The spectra of the fluorescent probe array after adding heavy metal ions to a solution, subject of excitation at various wavelengths, 260-660 nm. (a) Case of $\left[\mathrm{Cu}^{2+}\right]$, wherein the concentrations of the salt were $\mathrm{C}_{\mathrm{Cu}(\mathrm{NO}) 2}=0 \mathrm{M}$ (black line), $\mathrm{C}_{\mathrm{Cu}(\mathrm{NO}) 2}=2.41 \times 10^{-6} \mathrm{M}$ (red line), $\mathrm{C}_{\mathrm{Cu}(\mathrm{NO} 3) 2}=4.67 \times 10^{-6} \mathrm{M}$ (green line), $\mathrm{C}_{\mathrm{Cu}(\mathrm{NO} 3) 2}=6.8 \times 10^{-6} \mathrm{M}$ (blue line), and $\mathrm{C}_{\mathrm{Cu}(\mathrm{NO}) 2}=1.07 \times 10^{-5} \mathrm{M}$ (purple line). (b) Case of $\left[\mathrm{Pb}^{2+}\right]$, wherein the concentrations of the salt are $\mathrm{C}_{\mathrm{Pb}(\mathrm{NO} 3) 2}=0 \mathrm{M}$ (black line), $\mathrm{C}_{\mathrm{Pb}(\mathrm{NO} 3) 2}=2.8 \times 10^{-5} \mathrm{M}$ (red line), $\mathrm{C}_{\mathrm{Pb}(\mathrm{NO} 3) 2}=7.9 \times 10^{-5} \mathrm{M}$ (green line), $\mathrm{C}_{\mathrm{Pb}(\mathrm{NO} 3) 2}=1.24 \times 10^{-4} \mathrm{M}$ (blue line), $\mathrm{C}_{\mathrm{Pb}(\mathrm{NO} 3) 2}=3.26 \times 10^{-4} \mathrm{M}$ (aquamarine line), and $\mathrm{C}_{\mathrm{Pb}(\mathrm{NO}) 2}=5.87 \times 10^{-4} \mathrm{M}$ (purple one). The excitation wavelengths are shown in the figure.

The similar processes are observed when the lead salt has been added to the solution of the fluorescent probe array. The corresponding spectra changes are drawn in Figure $4 \mathrm{~b}$. We note a reduction in the fluorescence of eosin (from 91 a.u. to 56 a.u., that is, 39\%) and methylene blue (from 58 a.u. to 50 a.u., that is, $14 \%$ ), while the fluorescence of acridine yellow is first quenched (from 33 a.u. to 27 a.u., that is, $18 \%$ ) and then enhanced (from 27 a.u. to 37 a.u., that is, $37 \%$ ), making a substantial difference to the $\mathrm{Cu}^{+}$effect. Upon excitation at wavelengths of $450 \mathrm{~nm}$, corresponding to its absorption maximum at around $260 \mathrm{~nm}$, we observed an increase in its fluorescence upon addition of high lead concentrations from $3.26 \times 10^{-4} \mathrm{M}$. This observed increase in fluorescence under high $\left[\mathrm{Pb}^{2+}\right]$ concentrations cannot be explained by the effect of a heavy atom. However, there are some literature data showing that $\mathrm{Pb}$ can enhance fluorescence of probes under certain conditions [68-70].

When adding $\mathrm{Cd}^{2+}, \mathrm{Zn}^{2+}$, and $\mathrm{Cs}^{+}$ions to the solution of the dye array, the array response was also varied for each case. We summarize these findings in Figure 5. From 
adding $\mathrm{Cd}^{2+}$ ions, we found that fluorescence of all the three probes decreased: for acridine yellow from 22 a.u. to 16 a.u. (27\%), for eosin from 88 a.u. to 81 a.u. $(8 \%)$, and for methylene blue from 56 a.u. to 48 a.u. (14\%). However, the rate of these quenchings was different. It can be seen from Figure 5a that acridine yellow and methylene blue fluorescence reduced more uniformly than with eosin. Contrastingly, the addition of $\mathrm{Zn}^{2+}$ ions (Figure $5 \mathrm{~b}$ ) suppressed the eosin fluorescence in another way. For comparison, as drawn in Figure 5c, the $\mathrm{Cs}^{+}$ions essentially did not quench the eosin fluorescence when excitation was set as $500 \mathrm{~nm}$, but we observed a noticeable quenching (16\%) of eosin fluorescence when excitation was set to $260 \mathrm{~nm}$. The acridine yellow and methylene blue peaks were quenched by $30 \%$ and $14 \%$, respectively.

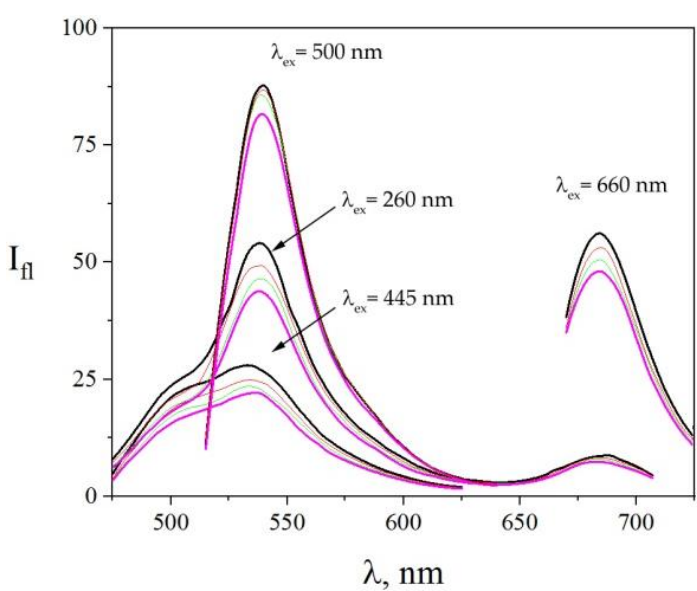

(a)

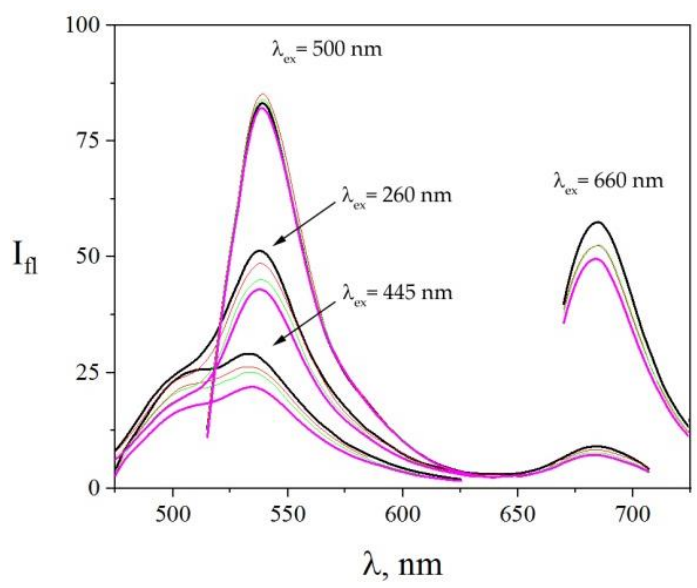

(c)

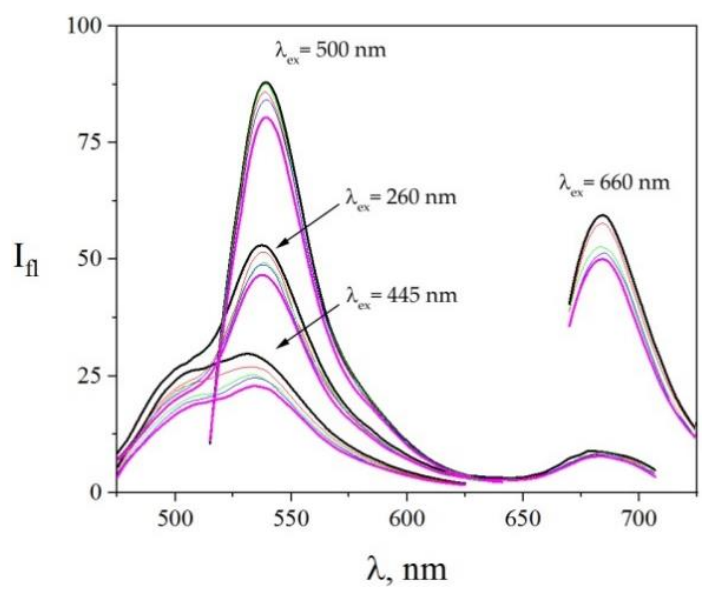

(b)

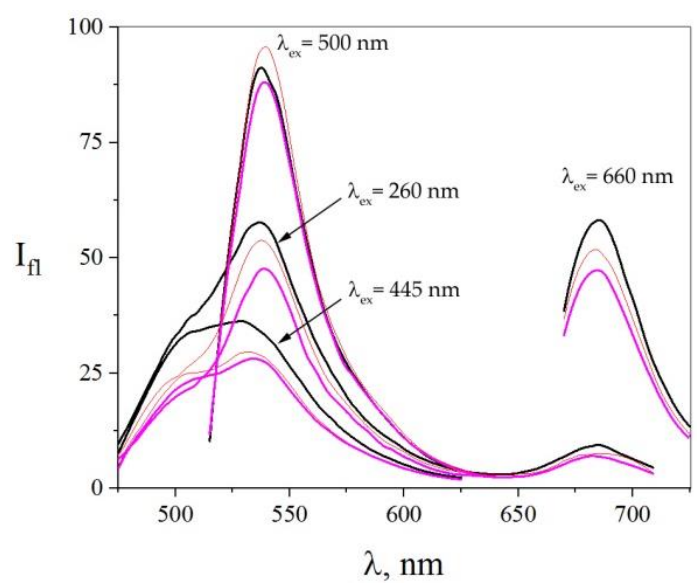

(d)

Figure 5. The spectra of the fluorescent probe array after adding heavy metal ions to a solution, subject to excitation at various wavelengths from 260 to $660 \mathrm{~nm}$. (a) In the case of $\left[\mathrm{Cd}^{2+}\right]$, the concentrations of the salt were $\mathrm{C}_{\mathrm{Cd}(\mathrm{NO}) 2}=0 \mathrm{M}$ (black line), $\mathrm{C}_{\mathrm{Cd}(\mathrm{NO}) 2}=1.17 \times 10^{-8} \mathrm{M}$ (red line), $\mathrm{C}_{\mathrm{Cd}(\mathrm{NO} 3) 2}=3.31 \times 10^{-8} \mathrm{M}$ (green line), and $\mathrm{C}_{\mathrm{Cd}(\mathrm{NO} 3) 2}=5.2 \times 10^{-8} \mathrm{M}$ (purple line). (b) In the case of $\left[\mathrm{Zn}^{2+}\right]$, the concentrations of the salt in the solutions were $\mathrm{C}_{\mathrm{Zn}(\mathrm{NO}) 2}=0 \mathrm{M}$ (black line), $C_{\mathrm{Zn}(\mathrm{NO} 3) 2}=1.46 \times 10^{-6} \mathrm{M}$ (red line), $\mathrm{C}_{\mathrm{Zn}(\mathrm{NO} 3) 2}=2.83 \times 10^{-6} \mathrm{M}$ (green line), $\mathrm{C}_{\mathrm{Zn}(\mathrm{NO} 3) 2}=4.11 \times 10^{-6} \mathrm{M}$ (blue line), and $\mathrm{C}_{\mathrm{Zn}(\mathrm{NO} 3) 2}=6.46 \times 10^{-6} \mathrm{M}$ (purple line). (c) In the case of $\left[\mathrm{Cs}^{+}\right]$, the concentrations of the salt were $\mathrm{C}_{\mathrm{CsCl}}=2.11 \times 10^{-6} \mathrm{M}$ (black line), $\mathrm{C}_{\mathrm{CsCl}}=2.11 \times 10^{-6} \mathrm{M}$ (red line), $\mathrm{C}_{\mathrm{CsCl}}=5.94 \times 10^{-6} \mathrm{M}$ (green line), and $\mathrm{C}_{\mathrm{CsCl}}=9.33 \times 10^{-6} \mathrm{M}$ (purple line). $(\mathrm{d})$ In the case of various volumes of distilled water: 0 (black line), 1/30 of initial volume (red line), and 5/30 of initial volume (purple line). The excitation wavelengths are shown in the figure. 
The distilled water was taken as a control sample for comparison to water not contaminated with heavy metal ions. The corresponding fluorescence spectra observed from the dye array are given in Figure $5 \mathrm{~d}$. As one can see, the spectra were still changed during the dilution but with different behavior when compared to metal salt solutions.

Overall, the results of spectral studies indicate that the nature of the reduction in the fluorescence intensity of the probed varies for different quenchers and upon dilution in pure water. Namely, the rates of quenching in dyes depended significantly on the type of heavy metals that yielded an opportunity to selectively identify them via collecting a total vector response of characteristic features observed for each dye in the array.

On the basis of the recorded spectra, we compiled tables of features corresponding to the response of the dye array under interaction with different metals. Each data point was normalized by the following formula:

$$
I=\frac{I_{A d d}}{I_{M S}},
$$

where $I_{M S}$ is a fluorescence intensity of the probe array without any addition, and $I_{a d d}$ is a fluorescence intensity of probe array upon the addition of test solutions under investigation.

These data points are compiled in Figure 6 to allow us easier comparison regarding their metal selective sensing capacity. The fluorescence intensities of the dyes were normalized to unity for further use as features of the test sample to combine a vector signal for pattern recognition processing via LDA algorithm. During the calibration of the algorithm, we used the experimentally obtained data sets, from which we obtained patterns corresponding to the following recognition classes: heavy metals of $\mathrm{Cu}, \mathrm{Pb}, \mathrm{Cd}, \mathrm{Zn}, \mathrm{Cs}$, and pure water.

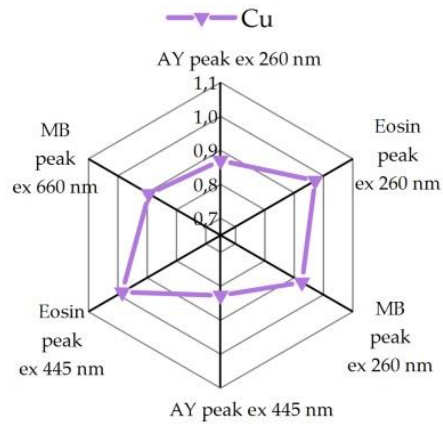

(a)

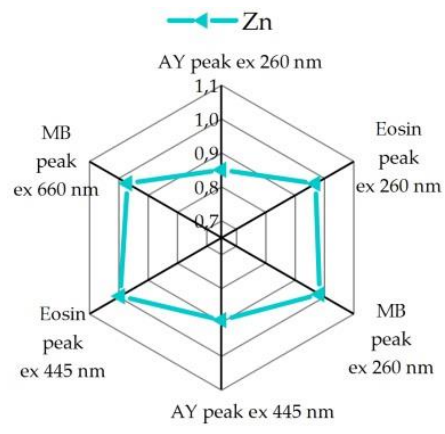

(d)

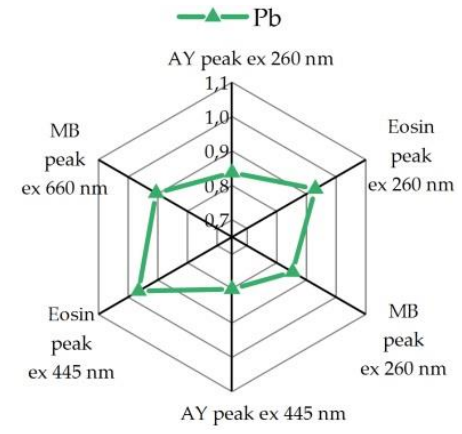

(b)

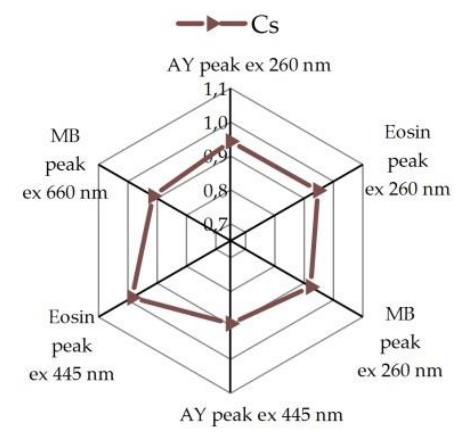

(e)

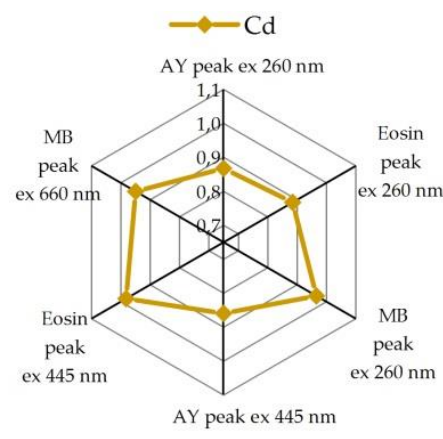

(c)

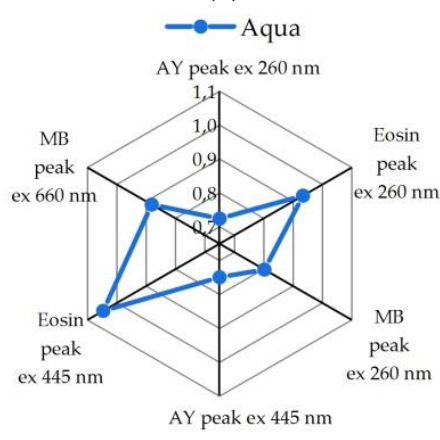

(f)

Figure 6. Normalized spectral responses (maxima of fluorescence intensities of three dyes upon excitation at $260 \mathrm{~nm}$ and at the maximum absorption of each dye) of the fluorescent probe array to various metal ions: $(\mathbf{a}) \mathrm{CuNO}_{3}\left(\mathrm{C}_{\mathrm{Cu}(\mathrm{NO} 3) 2}=2.41 \times 10^{-6} \mathrm{M}\right),(\mathbf{b}) \mathrm{PbNO}_{3}\left(\mathrm{C}_{\mathrm{Pb}(\mathrm{NO}) 2}=2.8 \times 10^{-5} \mathrm{M}\right)$, (c) $\mathrm{CdNO}_{3}\left(\mathrm{C}_{\mathrm{Cd}(\mathrm{NO} 3) 2}=1.17 \times 10^{-8} \mathrm{M}\right)$, (d) $\mathrm{ZnNO}_{3}\left(\mathrm{C}_{\mathrm{Zn}(\mathrm{NO} 3) 2}=1.46 \times 10^{-6} \mathrm{M}\right),($ e) $\mathrm{CsCl}$ $\left(\mathrm{C}_{\mathrm{CsCl}}=2.11 \times 10^{-6} \mathrm{M}\right),(\mathbf{f}) \mathrm{H}_{2} \mathrm{O}$. The pristine fluorescence intensities of the dyes in array are normalized to 1 . 
For each recognition class, 20 sets of initial data were used for training by introducing random errors into the initial data. According to the idea of the LDA algorithm, the projection is carried out in such a way as to ensure the maximum separation of classes regarding a scatter of data within a single class [71].

As a result of the learning process of the algorithm, the vector data are grouped into clusters corresponding to a particular type of analyte. By the distance between gravity centers of the clusters, one can judge the reliability of the classification. The LDA diagram that classifies the recorded data versus addition of $0.1 \mathrm{~mL}$ and $0.5 \mathrm{~mL}$ of each tested analyte solution to $3 \mathrm{~mL}$ solution containing the fluorescent probe array is shown in Figure 7. Here, we drew the 3D projection of the total 6D LDA coordinate system. It can be seen from the figure that the points on the diagram are grouped into clearly distinguishable clusters related to various analytes, which makes it possible to apply the methods of automatic signal recognition for their analysis. Thus, the LDA results show that the proposed system can be successfully used for selective recognition of heavy metal salts in water.

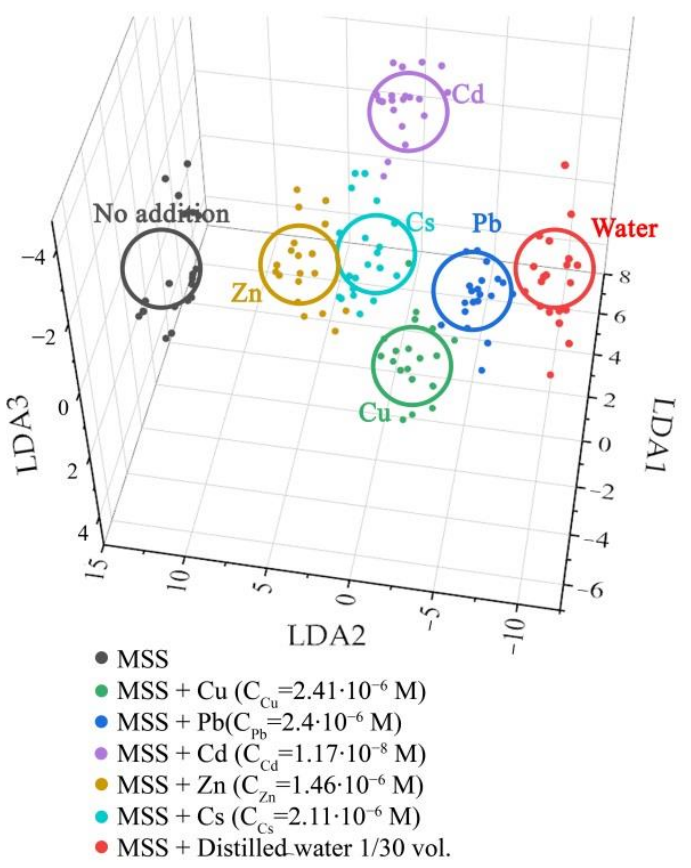

(a)

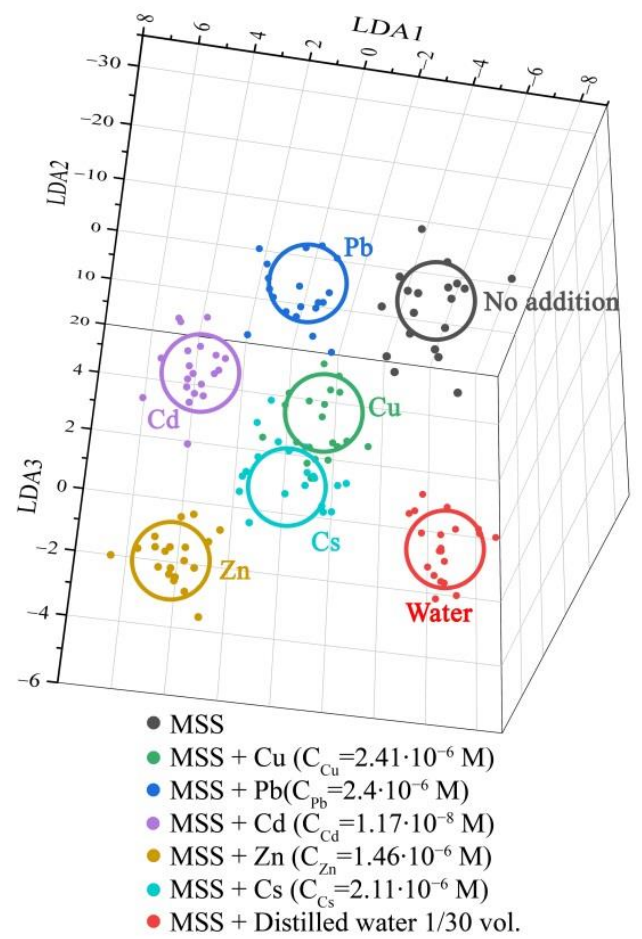

(b)

Figure 7. The 3D projection of the first three LDA components of 6D LDA coordinate system built to recognize vector signals of the fluorescent probe array versus seven test analytes added to $3 \mathrm{~mL}$ of solution containing the fluorescent probe array: (a) $0.1 \mathrm{~mL}$ volume of each test analyte; (b) $0.5 \mathrm{~mL}$ volume of each test analyte. The salt concentrations are drawn in the figure.

The experiments performed and the results of data processing allowed us to conclude that the fluorescence intensity of the luminescent dyes composing the fluorescent probe array was sensitive to the kind of various heavy metal ions to the solution. Due to the influence of various photophysical processes on the fluorescence process, changes in intensity were specific for various ions of heavy metals. Therefore, after the recognition algorithm was calibrated for the registration of predetermined substances, pattern recognition algorithms for the selective recognition of these substances in solution could be applied. Thus, this array can be employed for the selective determination of heavy metal salts in a liquid media.

The proposed approach is rather simple when compared to other ones, making it promising for practice. For instance, when using the above-noted methods $[45,47,49]$, some 
difficulties are caused by the need to prepare a large number of solutions of the test sample with fluorescent probes. This requires a large volume of the investigated medium, which is not always possible to carry out, especially when determining heavy metals in a biological media. Here, we have a significant simplification of sample preparation, since only one solution of the sample under testing at a small volume, around $0.1 \mathrm{~mL}$, was prepared, which is enough for a selective recognition.

\section{Conclusions}

Thus, in this work, a fluorescent probe array, consisting of a mixture of three luminescent dyes - eosin, methylene blue, and acridine yellow-was composed as an example of a low-cost ion-selective system. The fluorescence spectra were recorded upon excitation at different wavelengths, subject to change when adding heavy metal ions to the solution. It was found that the efficiency of fluorescence quenching differed both for different probes and for excitation wavelengths corresponding to $S_{0}-S_{2}$ and $S_{0}-S_{1}$ transfers of electrons in the dye's energy states. The observed differences in the changes of the spectra allowed us to generate a multisensor vector signal for selective recognition of various heavy metal ions employing the LDA algorithm.

This approach has promise because it allows one to use characteristics of complex photophysical processes occurring in the dyes composing the array as features to advance the selectivity of the ion detection. Still, further work is required to estimate the performance of the probe array under various interferences, at a long-term scale, according to specific practice applications. The mixes of various ions are also of special interest. With this purpose, other fluorescence probes should also be considered in the composition of the array.

Author Contributions: Conceptualization, A.G.M., V.V.S. and G.V.M.; methodology, A.G.M., V.V.S. and G.V.M.; software, A.G.M. and A.S.V.; formal analysis, A.G.M.; investigation, A.G.M., D.A.B. and G.V.M.; resources, A.G.M. and V.V.S.; data curation, A.G.M., D.A.B., A.S.V. and V.V.S.; writing, A.G.M., V.V.S. and G.V.M.; writing-review and editing, all authors; supervision, V.V.S. and G.V.M.; project administration, A.G.M. and V.V.S.; funding acquisition, A.G.M. and V.V.S. All authors have read and agreed to the published version of the manuscript.

Funding: This research received no external funding.

Institutional Review Board Statement: Not applicable.

Informed Consent Statement: Not applicable.

Data Availability Statement: All relevant data are contained within the article; further data are available from the corresponding author under request.

Acknowledgments: A. S. Varezhnikov and V. V. Sysoev thank the grant of the Russian Science Foundation, project No. 22-29-00793, for a partial support.

Conflicts of Interest: The authors declare no conflict of interest.

\section{References}

1. Buledi, J.A.; Amin, S.; Haider, S.I.; Bhanger, M.I.; Solangi, A.R. A review on detection of heavy metals from aqueous media using nanomaterial-based sensors. Environ. Sci. Pollut. Res. 2020, 28, 58994-59002. [CrossRef] [PubMed]

2. Smith, W.H. Air Pollution and Forests: Interactions between Air Contaminants and Forest Ecosystems; Springer Science \& Business Media: Berlin/Heidelberg, Germany, 2012.

3. Appelo, C.A.J.; Postma, D. Geochemistry, Groundwater and Pollution; CRC Press: Boca Raton, FL, USA, 2004.

4. Zamora-Ledezma, C.; Negrete-Bolagay, D.; Figueroa, F.; Zamora-Ledezma, E.; Ni, M.; Alexis, F.; Guerrero, V.H. Heavy metal water pollution: A fresh look about hazards, novel and conventional remediation methods. Environ. Technol. Innov. 2021, $22,101504$. [CrossRef]

5. Chibuike, G.U.; Obiora, S.C. Heavy metal polluted soils: Effect on plants and bioremediation methods. Appl. Environ. Soil Sci. 2014, 2014, e752708. [CrossRef]

6. Li, C.; Zhou, K.; Qin, W.; Tian, C.; Qi, M.; Yan, X.; Han, W. A review on heavy metals contamination in soil: Effects, sources, and remediation techniques. Soil Sediment Contam. Int. J. 2019, 28, 380-394. [CrossRef] 
7. Que, E.L.; Domaille, D.W.; Chang, C.J. Metals in neurobiology: Probing their chemistry and biology with molecular imaging. Chem. Rev. 2008, 108, 1517-1549. [CrossRef]

8. Jaishankar, M.; Tseten, T.; Anbalagan, N.; Mathew, B.B.; Beeregowda, K.N. Toxicity, mechanism and health effects of some heavy metals. Interdiscip. Toxicol. 2014, 7, 60-72. [CrossRef]

9. Flora, S.J.S.; Mittal, M.; Mehta, A. Heavy metal induced oxidative stress \& its possible reversal by chelation therapy. Indian J. Med. Res. 2008, 128, 501-523.

10. Tchounwou, P.B.; Yedjou, C.G.; Patlolla, A.K.; Sutton, D.J. Heavy metal toxicity and the environment. In Molecular, Clinical and Environmental Toxicology; Experientia Supplementum; Luch, A., Ed.; Springer: Berlin/Heidelberg, Germany, 2012; Volume 101, pp. 133-164. [CrossRef]

11. Eddaif, L.; Shaban, A.; Telegdi, J. Sensitive detection of heavy metals ions based on the calixarene derivatives-modified piezoelectric resonators: A review. Int. J. Environ. Anal. Chem. 2019, 99, 824-853. [CrossRef]

12. Špirić, Z.; Vučković, I.; Stafilov, T.; Kušan, V.; Frontasyeva, M. Air pollution study in Croatia using moss biomonitoring and ICP-AES and AAS analytical techniques. Arch. Environ. Contam. Toxicol. 2013, 65, 33-46. [CrossRef]

13. Drennan-Harris, L.R.; Wongwilawan, S.; Tyson, J.F. Trace determination of total mercury in rice by conventional inductively coupled plasma mass spectrometry. J. Anal. At. Spectrom. 2013, 28, 259-265. [CrossRef]

14. Lee, S.; Bong, S.; Ha, J.; Kwak, M.; Park, S.-K.; Piao, Y. Electrochemical deposition of bismuth on activated graphene-nafion composite for anodic stripping voltammetric determination of trace heavy metals. Sens. Actuators B Chem. 2015, 215, 62-69. [CrossRef]

15. Liang, Y.; Deng, B.; Shen, C.; Qin, X.; Liang, S. Determination of the binding sites and binding constants between Pb(II) and DNA using capillary electrophoresis combined with electrothermal atomic absorption spectrometry. J. Anal. At. Spectrom. 2015, 30, 903-908. [CrossRef]

16. Palisoc, S.; Vitto, R.I.M.; Natividad, M. Determination of heavy metals in herbal food supplements using bismuth/multi-walled carbon nanotubes/Nafion modified graphite electrodes sourced from waste batteries. Sci. Rep. 2019, 9, 18491. [CrossRef]

17. Willis, J.B. Determination of lead and other heavy metals in urine by atomic absorption spectroscopy. Anal. Chem. 1962, 34, 614-617. [CrossRef]

18. Kenawy, I.M.M.; Hafez, M.A.H.; Akl, M.A.; Lashein, R.R. Determination by AAS of some trace heavy metal ions in some natural and biological samples after their preconcentration using newly chemically modified chloromethylated polystyrene-PAN ion-exchanger. Anal. Sci. 2000, 16, 493-500. [CrossRef]

19. Mohamed, R.A.; Abdel-Lateef, A.M.; Mahmoud, H.H.; Helal, A.I. Determination of trace elements in water and sediment samples from Ismaelia Canal using ion chromatography and atomic absorption spectroscopy. Chem. Speciat. Bioavailab. 2012, $24,31-38$. [CrossRef]

20. Venkata Subba Raju, O.; Prasad, P.M.N.; Rami Reddy, Y.V. Determination of heavy metals in ground water by Icp-MS in selected coastal areas of Spsr Nellore District, Andhra Pradesh, India. IJSR Int. J. Sci. Res. 2013, 2, 78-81. [CrossRef]

21. Lewen, N.; Mathew, S.; Schenkenberger, M.; Raglione, T. A rapid ICP-MS screen for heavy metals in pharmaceutical compounds. J. Pharm. Biomed. Anal. 2004, 35, 739-752. [CrossRef]

22. Zhao, F.; Chen, Z.; Zhang, F.; Li, R.; Zhou, J. Ultra-sensitive detection of heavy metal ions in tap water by laser-induced breakdown spectroscopy with the assistance of electrical-deposition. Anal. Methods 2010, 2, 408-414. [CrossRef]

23. Chen, Y.; Zhang, Q.; Li, G.; Li, R.; Zhou, J. Laser ignition assisted spark-induced breakdown spectroscopy for the ultra-sensitive detection of trace mercury ions in aqueous solutions. J. Anal. At. Spectrom. 2010, 25, 1969-1973. [CrossRef]

24. Lee, Y.; Oh, S.-W.; Hanb, S.-H. Laser-induced breakdown spectroscopy (LIBS) of heavy metal ions at the sub-parts per million level in water. Appl. Spectrosc. 2012, 66, 1385-1396. [CrossRef] [PubMed]

25. Guinn, V.P.; Wagner, C.D. Instrumental neutron activation analysis. Anal. Chem. 1960, 32, 317-323. [CrossRef]

26. Glascock, M. An Overview of Neutron Activation Analysis. 2003. Available online: http:// fs.teledos.gr:2206/\%3ERESEARCH\% 20PUBLICATIONS/NUCLEAR\%20TECHNOLOGY\%20-\%20ENGINEERING/Elemental\%20Analysis/An\%20Overview\%20 of\%20Neutron\%20Activation\%20Analysis.\%20M.\%20D.\%20Glascock.pdf (accessed on 20 December 2021).

27. Yusuf, S.; Fisli, A.; Wardhani, S. The role of NAA in the environmental studies. Quantitative determination of heavy metals pollutant on environmental samples. In Proceedings of the JAERI-CONF-2003-004, Tokai, Japan, 7 March 2003; Volume 37, p. 37002233. [CrossRef]

28. Spelthahn, H.; Kirsanov, D.; Legin, A.; Osterrath, T.; Schubert, J.; Zander, W.; Schöning, M.J. Development of a thin-film sensor array for analytical monitoring of heavy metals in aqueous solutions. Phys. Stat. Sol. (A) Appl. Mater. Sci. 2012, 209, 885-891. [CrossRef]

29. Lu, Y.; Liang, X.; Niyungeko, C.; Zhou, J.; Xu, J.; Tian, G. A review of the identification and detection of heavy metal ions in the environment by voltammetry. Talanta 2018, 178, 324-338. [CrossRef] [PubMed]

30. Emons, H.; Baade, A.; Schöning, M.J. Voltammetric determination of heavy metals in microvolumes of rain water. Electroanalysis 2000, 12, 1171-1176. [CrossRef]

31. Papkovsky, D.B.; Papkovskaia, N.; Smyth, A.; Kerry, J.; Ogurtsov, V.I. Phosphorescent sensor approach for non-destructive measurement of oxygen in packaged foods: Optimisation of disposable oxygen sensors and their characterization over a wide temperature range. Anal. Lett. 2000, 33, 1755-1777. [CrossRef] 
32. Hassoun, A.; Sahar, A.; Lakhal, L.; Aït-Kaddour, A. Fluorescence spectroscopy as a rapid and non-destructive method for monitoring quality and authenticity of fish and meat products: Impact of different preservation conditions. LWT 2019, 103, 279-292. [CrossRef]

33. Geddes, C.D. Optical halide sensing using fluorescence quenching: Theory, simulations and applications-A review. Meas. Sci. Technol. 2001, 12, R53. [CrossRef]

34. De Acha, N.; Elosúa, C.; Corres, J.M.; Arregui, F.J. Fluorescent sensors for the detection of heavy metal ions in aqueous media. Sensors 2019, 19, 599. [CrossRef]

35. Lian, J.; Xu, Q.; Wang, Y.; Meng, F. Recent developments in fluorescent materials for heavy metal ions analysis from the perspective of forensic chemistry. Front. Chem. 2020, 8, 593291. [CrossRef]

36. Nurerk, P.; Kanatharana, P.; Bunkoed, O. A selective determination of copper ions in water samples based on the fluorescence quenching of thiol-capped CdTe quantum dots. Luminescence 2016, 31, 515-522. [CrossRef] [PubMed]

37. Wu, F.-Y.; Bae, S.W.; Hong, J.-I. A selective fluorescent sensor for Pb(II) in water. Tetrahedron Lett. 2006, 47, 8851-8854. [CrossRef]

38. Antony, E.J.; Raj, M.; Paulpandi, R.Q.; Paulraj, M.S.; Enoch, I.V.M.V. A highly selective fluorescent sensor for Pb ${ }^{2+}$ based on a modified $\beta$-cyclodextrin. J. Fluoresc. 2015, 25, 1031-1036. [CrossRef]

39. Wan, J.; Duan, W.; Chen, K.; Tao, Y.; Dang, J.; Zeng, K.; Ge, Y.; Wu, J.; Liu, D. Selective and sensitive detection of Zn(II) ion using a simple peptide-based sensor. Sens. Actuators B Chem. 2018, 255, 49-56. [CrossRef]

40. Vendrell, M.; Zhai, D.; Er, J.C.; Chang, Y.-T. Combinatorial strategies in fluorescent probe development. Chem. Rev. 2012, 112, 4391-4420. [CrossRef] [PubMed]

41. Shieh, P.; Dien, V.T.; Beahm, B.J.; Castellano, J.M.; Wyss-Coray, T.; Bertozzi, C.R. CalFluors: A universal motif for fluorogenic azide probes across the visible spectrum. J. Am. Chem. Soc. 2015, 137, 7145-7151. [CrossRef] [PubMed]

42. Kobayashi, H.; Longmire, M.R.; Ogawa, M.; Choyke, P.L. Rational chemical design of the next generation of molecular imaging probes based on physics and biology: Mixing modalities, colors and signals. Chem. Soc. Rev. 2011, 40, 4626-4648. [CrossRef]

43. Costa, F.S.L.; Silva, P.P.; Morais, C.L.M.; Theodoro, R.C.; Arantes, T.D.; Lima, K.M.G. Comparison of multivariate classification algorithms using EEM fluorescence data to distinguish: Cryptococcus neoformans and Cryptococcus gattii pathogenic fungi. Anal. Methods 2017, 9, 3968-3976. [CrossRef]

44. Dankowska, A.; Małecka, M.; Kowalewski, W. Detection of plant oil addition to cheese by synchronous fluorescence spectroscopy. Dairy Sci. Technol. 2015, 95, 413-424. [CrossRef]

45. Chen, L.; Li, L.; Wu, D.; Tian, X.; Xia, D.; Lu, L.; Yang, C.; Nie, Y. Construction of multi-channel fluorescence sensor array and its application for accurate identification and sensitive quantification of multiple metal ions. Sens. Actuators B Chem. 2020, 303, 127277. [CrossRef]

46. Smith, D.G.; Mitchell, L.; New, E.J. Pattern recognition of toxic metal ions using a single-probe thiocoumarin array. Analyst 2019, 144, 230-236. [CrossRef] [PubMed]

47. Cao, Z.; Cao, Y.; Kubota, R.; Sasaki, Y.; Asano, K.; Lyu, X.; Zhang, Z.; Zhou, Q.; Zhao, X.; Xu, X.; et al. Fluorescence anion chemosensor array based on pyrenylboronic acid. Front. Chem. 2020, 8, 414. [CrossRef] [PubMed]

48. Moczko, E.; Mirkes, E.M.; Cáceres, C.; Gorban, A.N.; Piletsky, S. Fluorescence-based assay as a new screening tool for toxic chemicals. Sci. Rep. 2016, 6, 33922. [CrossRef] [PubMed]

49. He, W.; Luo, L.; Liu, Q.; Chen, Z. Colorimetric sensor array for discrimination of heavy metal ions in aqueous solution based on three kinds of thiols as receptors. Anal. Chem. 2018, 90, 4770-4775. [CrossRef]

50. Gruzina, T.G.; Zadorozhnyaya, A.M.; Gutnik, G.A.; Vember, V.V.; Ulberg, Z.R.; Kanyuk, N.I.; Starodub, N.F. A bacterial multisensor for determination of the contents of heavy metals in water. J. Water Chem. Technol. 2007, 29, 50-53. [CrossRef]

51. Margulies, D.; Rout, B. Multi-Sensor Array Compound and Methods of Use Thereof. U.S. Patent 10,017,525, 16 July 2013.

52. Melnikov, A.G.; Melnikov, G.V.; Varezhnikov, A.S.; Efremova, V.V.; Kuenbaeva, V.R.; Dykin, V.S.; Sysoev, V.V. The fluorescencent multi-sensor array to selectively detect a presence of various heavy metals in aqua solutions. In Proceedings of the 2016 International Conference on Actual Problems of Electron Devices Engineering, APEDE, Saratov, Russia, 22-23 September 2016; Volume 2, p. 7879034. [CrossRef]

53. Derayea, S.M.; Nagy, D.M. Application of a xanthene dye, eosin y, as spectroscopic probe in chemical and pharmaceutical analysis; A review. Rev. Anal. Chem. 2018, 37, 20170020. [CrossRef]

54. Abolghasemi, M.-M.; Ghorbani-Cheghamarani, A.; Babakhanian, A. A novel electrochemical sensing platform based on $\mathrm{Pt} / \mathrm{PPy} /$ Eosin-Y for the determination of cadmium. New J. Chem. 2017, 41, 11335-11341. [CrossRef]

55. Teuber, M.; Rögner, M.; Berry, S. Fluorescent probes for non-invasive bioenergetic studies of whole cyanobacterial cells. Biochim. Et Biophys. Acta Bioenerg. 2001, 1506, 31-46. [CrossRef]

56. Kulikova, T.; Porfireva, A.; Rogov, A.; Evtugyn, G. Electrochemical DNA sensor based on acridine yellow adsorbed on glassy carbon electrode. Sensors 2021, 21, 7763. [CrossRef]

57. Liu, S.P.; Sa, C.; Hu, X.L.; Kong, L. Fluorescence quenching method for the determination of sodium carboxymethyl cellulose with acridine yellow or acridine orange. Spectrochim. Acta-Part A Mol. Biomol. Spectrosc. 2006, 64, 817-822. [CrossRef]

58. Amat, A.M.; Arques, A.; Galindo, F.; Miranda, M.A.; Santos-Juanes, L.; Vercher, R.F.; Vicente, R. Acridine yellow as solar photocatalyst for enhancing biodegradability and eliminating ferulic acid as model pollutant. Appl. Catal. B Environ. 2007, 73, 220-226. [CrossRef]

59. Xu, L.; Yan, X.; Yuan, C. An unexpected dual-response pH probe based on acridine. RSC Adv. 2018, 8, 35289-35293. [CrossRef] 
60. Ginimuge, P.R.; Jyothi, S.D. Methylene blue: Revisited. J. Anaesthesiol. Clin. Pharmacol. 2010, 26, 517-520. [PubMed]

61. Selvam, S.; Sarkar, I. Bile salt induced solubilization of methylene blue: Study on methylene blue fluorescence properties and molecular mechanics calculation. J. Pharm. Anal. 2017, 7, 71-75. [CrossRef] [PubMed]

62. Huang, X.; Li, Z.; Cao, T.; Cai, Q.; Zeng, C.; Fu, H.; Hu, L. A methylene blue-based near-infrared fluorescent probe for rapid detection of hypochlorite in tap water and living cells. RSC Adv. 2018, 8, 14603-14608. [CrossRef]

63. Yaroslavsky, A.N.; Feng, X.; Muzikansky, A.; Hamblin, M.R. Fluorescence polarization of methylene blue as a quantitative marker of breast cancer at the cellular level. Sci. Rep. 2019, 9, 940. [CrossRef] [PubMed]

64. Olmsted, J., III. Calorimetric determinations of absolute fluorescence quantum yields. J. Phys. Chem. 1979, 83, 2581-2584. [CrossRef]

65. Seybold, P.G.; Gouterman, M.; Callis, J. Calorimetric, photometric and lifetime determinations of fluorescence yields of fluorescein dyes. Photochem. Photobiol. 1969, 9, 229-242. [CrossRef]

66. Redmond, R.W.; Gamlin, J.N. A compilation of singlet oxygen yields from biologically relevant molecules. Photochem. Photobiol. 1999, 70, 391-475. [CrossRef]

67. Pedregosa, F.; Varoquaux, G.; Gramfort, A.; Michel, V.; Thirion, B.; Grisel, O.; Blondel, M.; Prettenhofer, P.; Weiss, R.; Dubourg, V.; et al. Scikit-learn: Machine learning in Python. J. Mach. Learn. Res. 2011, 12, 2825-2830. [CrossRef]

68. Arunjegan, A.; Rajaji, P.; Sivanesan, S.; Panneerselvam, P. A Turn-ON fluorometric biosensor based on ssDNA immobilized with a metal phenolic nanomaterial for the sequential detection of $\mathrm{Pb}$ (ii) and epirubicin cancer drug. RSC Adv. 2021, 11, 12361-12373. [CrossRef]

69. Wu, G.; Li, M.; Zhu, J.; Lai, K.W.C.; Tong, Q.; Lu, F. A highly sensitive and selective turn-on fluorescent probe for Pb(II) ions based on a coumarin-quinoline platform. RSC Adv. 2016, 6, 100696-100699. [CrossRef]

70. Chae, M.-Y.; Yoon, J.; Czarnik, A.W. Chelation-enhanced fluorescence chemosensing of $\mathrm{Pb}(\mathrm{II})$, an inherently quenching metal ion. J. Mol. Recognit. 1996, 9, 297-303. [CrossRef]

71. Sysoev, V.V.; Kiselev, I.; Trouillet, V.; Bruns, M. Enhancing the gas selectivity of single-crystal $\mathrm{SnO}_{2}: \mathrm{Pt}$ thin-film chemiresistor microarray by $\mathrm{SiO}_{2}$ membrane coating. Sens. Actuators B Chem. 2013, 185, 59-69. [CrossRef] 